\title{
TESTIMONIO Y FICCIÓN EN LA ARGENTINA DE LA POSTDICTADURA. LOS RELATOS DEL SOBREVIVIENTE-TESTIGO
}

\author{
Victoria García \\ Facultad de Filosofía y Letras, Universidad de Buenos Aires, CONICET \\ victoriaggarcia@gmail.com
}

\section{RESUMEN / ABSTRACT}

La literatura testimonial, cuyo origen histórico remite al proceso político-cultural latinoamericano de los años 60-70, expone particularidades relevantes al considerar su desarrollo en la Argentina postdictatorial. El presente artículo se centra en la producción literaria testimonial argentina de la década de 1980. En primer lugar, proponemos un enfoque panorámico de la historia de la literatura testimonial argentina, desde su auge inicial a comienzos de la década de 1970 hasta la contemporaneidad. En segundo lugar, abordamos el análisis de tres obras testimoniales producidas por escritores argentinos en los años 80: Recuerdo de la muerte de Miguel Bonasso, La Escuelita de Alicia Partnoy y Pasos bajo el agua de Alicia Kozameh. El análisis considera los efectos de sentido asociados a las distintas interrelaciones entre testimonio y ficción que los relatos despliegan en la representación de la experiencia concentracionaria.

PALABRAS ClAVE: literatura testimonial, postdictadura, sobreviviente-testigo, ficción, discurso factual.

The historical origin of testimonial literature is related to the Latin American political cultural process in the 60-70s, but testimonial literature as a genre exposes significant particularities when its development in postdictatorial Argentina is considered. Therefore, this paper focuses on Argentine testimonial literature produced during the 1980 decade. Firstly, we present a panoramic approach to the history of Argentine testimonial literature, beginning with its initial boom in the 70s, and taking up to the contemporary period. Secondly, we analyze three works produced by Argentine writers during the 1980 decade: Recuerdo de la muerte by Miguel Bonasso, La Escuelita by Alicia Partnoy and Pasos bajo el agua by Alicia Kozameh. The study shows the different interrelations between testimony and fiction, which are displayed in the texts as peculiar ways of representing the concentrationary experience.

KEYWORDS:Testimonial literature, post-dictatorship, survivor-witness, fiction, factual discourse. 


\section{INTRODUCCIÓN: HACIA UNA HISTORIA ARGENTINA DE LA LITERATURA TESTIMONIAL}

El origen histórico del testimonio como género literario reenvía al proceso político-cultural latinoamericano de los años 60-70. En ese contexto, la instauración progresiva de criterios políticos de legitimación literaria propició la institucionalización de un tipo de literatura que ciertos actores del campo cultural consideraban valiosa para la difusión de la tarea revolucionaria en América Latina ${ }^{1}$. No se trató, sin embargo, del surgimiento de un género literario ex nihilo. Más bien, el origen de la literatura testimonial latinoamericana designa el momento en que los círculos literarios incorporaron a sus categorías de producción artística un nombre de género hasta entonces ajeno a la literatura, el testimonio, junto a ciertas prácticas de escritura que dicho nombre genérico permitía englobar: especialmente, aquellas que daban cuenta de un haber estado allí, en el agitado proceso político de la etapa ${ }^{2}$. La incorporación de la "nueva" categoría genérica posibilitaba, en esa línea, proporcionar identidad y jerarquía literarias a ciertas producciones escritas ya existentes, que habían surgido por fuera de lo que se consideraba estrictamente literatura: textos de investigación periodística, como Operación masacre de Rodolfo Walsh (1957), o relatos etnológicos, como Biografía de un cimarrón de Miguel Barnet (1966). Al mismo tiempo, la consagración literaria del (nombre de) género testimonio se dirigió a fomentar la producción de un tipo particular de literatura y, más aun, a orientarla desde el punto de vista de ciertos parámetros que, a partir de entonces, pasarían a aparecer como característicos del género testimonial. Así ocurrió con el certamen literario de Casa de las Américas,

En efecto, trabajos recientes sobre el testimonio subrayan la relación entre su institucionalización y el estado del campo literario latinoamericano en los años 60-70. Así, Quintero Herencia ubicó en las "Palabras a los intelectuales" pronunciadas por Fidel Castro en 1961 ciertas orientaciones para la producción literaria que anticipan la literatura testimonial tal como la desarrolló Barnet (371). Gilman incluye al testimonio entre los "nuevos formatos de un arte revolucionario", que los sectores politizados del campo literario latinoamericano promovieron desde el final de la década de 1960 (339). Morejón Arnaiz ha analizado la valoración positiva de modalidades testimoniales y documentales de representación, que se instaló paulatinamente en el discurso de Casa de las Américas a lo largo de los años 60. Peris Blanes ("La palabra"), en tanto, señaló el vínculo entre el auge del imaginario antiintelectualista en Cuba y la institucionalización de la literatura testimonial.

2 Seguimos a Schaeffer en cuanto a la centralidad de las denominaciones genéricas en el estudio de los géneros discursivos y literarios (Qué es 46). 
que desde 1970 incluyó al testimonio entre sus categorías premiadas, y cuya convocatoria inicial estipulaba que las obras que aspiraban a ser consideradas legítimamente testimoniales debían documentar "de forma directa, un aspecto de la realidad latinoamericana" (Ochando Aymerich 32).

Si bien la institucionalización del género testimonial concierne al campo literario latinoamericano, cuya sede básica en los politizados años 60-70 la constituía La Habana, hay que destacar que un escritor argentino, Rodolfo Walsh, tuvo protagonismo en ese proceso inicial de institucionalización. Walsh fue uno de los jurados de la categoría testimonio del certamen de Casa de 1970 -junto a Ricardo Pozas y Raúl Roa- y, más en general, se lo consideró un escritor pionero y paradigmático del recientemente creado género, en virtud de su obra Operación masacre -publicada originalmente en 1957-3. En efecto, con ese libro, el escritor argentino instaló una variante del género, la "novela" sobre hechos reales, que no solo anticipaba las técnicas literarias después difundidas por la non-fiction estadounidense, sino además se servía de ellas para denunciar un episodio de violencia estatal de amplia relevancia en la historia argentina de los años 60-70-i-e. el brutal procedimiento represivo que el gobierno de facto de la "Revolución Libertadora" ejecutó frente a un levantamiento militar-cívico en junio de 1956 (Melón Pirro 67-75)-. En esa línea, el texto cobraba sentido a partir de una relación estrecha entre literatura y política, que quedaba expresada en su misma forma narrativa. Operación masacre constituyó, por eso, un precedente ineludible para escritores que, después de Walsh, hicieron de su literatura un modo de intervención política y que, desde esa perspectiva, apelaron al testimonio como opción estética legítima dentro de sus proyectos narrativos ${ }^{4}$.

3 Subrayemos que Operación masacre fue conocida fuera de la Argentina solo desde el final de la década de 1960. En 1970 y 1971, el libro fue editado en Cuba -por Casa de las Américas y Huracán, respectivamente-. En las discusiones de los organizadores del premio Casa que culminaron en la introducción de la categoría Testimonio, el texto de Walsh apareció como "una de las obras de mayor calidad, altamente representativa de ese género" (Galich 124. Véase también Rama 293 y Fornet 139). En 1972, el teólogo y filósofo españolvenezolano Pedro Trigo caracterizaba al libro como "una de las obras de testimonio y denuncia de la realidad latinoamericana de hoy", "un trabajo de años, apasionado, pero concienzudo, riguroso" (93-94).

La figura de Walsh, y en particular Operación masacre como su obra clave, aparecen evocados explícitamente como referencias literarias en otros textos relevantes de la literatura testimonial argentina, desde los años 70 hasta la contemporaneidad. Así, Los pasos previos de Francisco Urondo (1974) incluye textos intercalados de Walsh y del periodista Leopoldo 
El papel de Rodolfo Walsh en el surgimiento literario del testimonio permite introducir el tema más amplio del desarrollo de la literatura testimonial en la Argentina y, en la misma línea, la necesidad de una aproximación integral a su historia y a sus particularidades, dentro de un género que, como señalamos, surgió en el ámbito latinoamericano. Este enfoque constituye aún una tarea pendiente para la crítica literaria. De hecho, la literatura argentina está prácticamente ausente de los primeros trabajos críticos sobre el testimonio, que vieron en el género una expresión de la subalternidad narrativa ${ }^{5}$. En trabajos posteriores, en los que el testimonio aparece como vehículo de la memoria social sobre los procesos dictatoriales latinoamericanos, la narrativa testimonial argentina tiene un lugar central ${ }^{6}$. No obstante, puesto que el grueso de la crítica sobre el testimonio en la Argentina se ha enfocado en la postdictadura, aún quedan por ser analizadas las conexiones y las discontinuidades entre la literatura testimonial de las últimas tres décadas y la producida en los años 60-70, cuando el género comenzaba a instalarse en el ámbito latinoamericano.

Así, si -a modo de introducción panorámica- se considera globalmente el desarrollo de la literatura testimonial argentina desde los años 60, es posible afirmar que el género alcanzó un momento de auge en el contexto de su institucionalización latinoamericana, esto es, en la primera mitad de la

Barraza, en uno de los cuales se afirma: “Operación masacre' de Rodolfo Walsh marcó el camino a seguir" (111). En Recuerdo de la muerte, de Miguel Bonasso (1984) (vid. infra), el autor sitúa a Walsh como su "maestro", imitando deliberadamente un fragmento de Operación masacre (405). En el más reciente Diario de una princesa montonera, de Mariana Eva Perez (2012), la protagonista se declara "fan de Rodolfo Walsh" (71).

Véase, por ejemplo, el clásico artículo de John Beverley, "Anatomía del testimonio". En este y otros trabajos sobre el género producidos entre el final de los años $80 \mathrm{y}$ el comienzo de los 90 , fue la literatura testimonial centroamericana la que cobró centralidad para la crítica. Dicha centralidad se asoció al compromiso asumido por cierta intelectualidad estadounidense, en relación con las luchas populares que se desarrollaron en aquella región a partir de la Revolución Sandinista (Palazón Sáez 95).

6 Nos referimos a trabajos como los de Rossana Nofal (La escritura), Beatriz Sarlo (Tiempo pasado), Nora Strejilevich y Adriana Goicochea, enteramente dedicados al género testimonial en sus expresiones contemporáneas. Desde la perspectiva que los orienta, el testimonio se definiría por su vínculo con una "memoria de víctimas y sobrevivientes" (Nofal, La escritura 39); por conformar una "suma histórica contra el olvido" (33). Más allá de la crítica local, otros trabajos, como los reunidos en Recordar para pensar y en la compilación Badaró y Forné, asimismo reflexionan sobre la relación entre testimonio y memoria, otorgando relevancia a la literatura argentina postdictatorial. 
década de 1970. En ese marco, varios escritores, comprometidos de distintas formas con las luchas de liberación en Argentina y América Latina adoptaron estrategias narrativas asociadas a la literatura testimonial: Francisco Urondo -La patria fusilada (1973) y Los pasos previos (1974)-, Tomás Eloy Martínez -La pasión según Trelew (1974)- y hasta Julio Cortázar -Libro de Manuel (1973)-. Walsh, por su parte, había publicado para ese momento sucesivas versiones de Operación masacre, pero también ¿Quién mató a Rosendo? (1969) y Caso Satanowsky (1973), obras que presentan una estructura narrativa similar, y características de la escritura testimonial y/o documental ${ }^{7}$.

Luego del auge testimonial de los primeros años 70, la violencia paraestatal desplegada a partir de $1974 \mathrm{y}$, sobre todo, la represión estatal sistemática implementada en la dictadura que se inició en 1976, representaron contextos adversos para la escritura testimonial. En este sentido, la "Carta de un escritor a la Junta Militar", de Rodolfo Walsh, constituye un claro ejemplo de las condiciones de producción y circulación de la literatura testimonial durante la dictadura. Allí, Walsh se declaraba "fiel al compromiso [...] de dar testimonio en los años difíciles" (213), pero las circunstancias políticas del momento restringían el alcance de su testimonio: el texto circuló localmente en forma clandestina, y su divulgación pública durante la dictadura se produjo en el exterior, como parte de la denuncia internacional del terrorismo estatal. Walsh, como es sabido, fue asesinado el mismo día en que difundió la "Carta" ${ }^{8}$. En el mismo sentido, hay que notar que las expresiones de la narrativa argentina consideradas paradigmáticas de la etapa dictatorial, como Nadie nada nunca de Juan José Saer y Respiración artificial de Ricardo Piglia -ambas de 1980-, eluden el reenvío directo a la realidad político-social con el recurso a la elipsis y a la alegoría (Sarlo, Escritos 345; Dalmaroni 155): se ubican,

7 Hemos analizado en otro lugar la obra testimonial de Walsh, producida entre 1957 y 1973 (García, La obra testimonial). Asimismo, hemos estudiado los puntos de contacto y las diferencias entre las narrativas testimoniales-documentales de Walsh, Urondo y Cortázar (García, "Testimonio y literatura"). Para un estudio específico sobre Urondo como escritor testimonial, véase el trabajo de Graselli (cap. IX). Acerca de Eloy Martínez y la escritura testimonial, puede consultarse el enfoque de Castillo.

La "Carta" de Walsh no solo ejemplifica las condiciones de producción de la literatura durante la dictadura sino, más ampliamente, expone los modos de circulación del discurso testimonial emitido con objetivos de denuncia sobre el terror dictatorial. Así, según Crenzel: "los denunciantes pugnaron por hacerse oír y tornarse visibles en el espacio público, pero, a pesar de ello, estuvieron aislados por largos años, extraños a las multitudes, imposibilitados de cuestionar el monopolio de la palabra e interpretación dictatorial" (377). 
así, en las antípodas de la denuncia abierta sobre hechos sociales y políticos, ligada a la estética testimonial ${ }^{9}$.

La literatura testimonial argentina volvió a cobrar impulso a partir de la recuperación de la democracia en 1983. En efecto, se inauguró entonces la "era del testigo" argentina (Wieviorka 96), con la emergencia en la esfera pública de las víctimas de la represión dictatorial y la proliferación de relatos sobre la detención clandestina (Calveiro, "Testimonio y memoria" 69; Jelin 113). La investigación de la CONADEP que dio lugar al Nunca más (1984) y el Juicio a las Juntas (1985), fueron las expresiones centrales de este proceso jurídico y político, cuyas implicaciones socio-culturales profundas no dejaron de exhibirse en la producción literaria. En efecto, la literatura testimonial reactivada en el contexto democrático expone transformaciones significativas respecto de las manifestaciones del género surgidas en los primeros años 70. Así, si en aquella época el testimonio se concebía como intervención literaria en el presente, orientada a la denuncia de un orden social considerado injusto y a la difusión de la creencia en la posibilidad de transformarlo, desde los años 80 la literatura testimonial pasa a constituir un espacio de reconstrucción de la memoria colectiva y, con ello, un género que mira al pasado ${ }^{10}$. Los hechos traumáticos del terrorismo de Estado entre 1976 y 1983, pero también las militancias de los años 60-70, toman protagonismo

9 Tampoco son estrictamente testimoniales ni documentales las novelas que David Foster analiza bajo la categoría de "Narrativa argentina testimonial durante los años del 'Proceso"': Flores robadas en los jardines de Quilmes de Jorge Asís (1980), Las muecas del miedo de Enrique Medina (1981), Informe bajo llave de Marta Lynch (1983), entre otras. En efecto, aunque estos textos plantean referencias manifiestas a la realidad política argentina en la dictadura, no dejan de ser ficción, y no presentan rasgos del testimonio o del documento en sus modos de representación textual. La única excepción dentro del corpus considerado por Medina es Prisoner without a name, cell without a number de Jacobo Timmerman (1981), que fue publicado inicialmente en Estados Unidos, y expone el testimonio del autor sobre su experiencia como preso en los centros de detención clandestina en la dictadura.

10 En este sentido, la literatura testimonial argentina expone desplazamientos históricos similares a los que Jaume Peris Blanes ha descrito para el testimonio chileno. Así, según el autor, su desarrollo desde 1973 hasta la contemporaneidad muestra el pasaje de una etapa en la que primaba el objetivo de denuncia, a otra en la que se produce una "absorción progresiva de todos los discursos sobre la violencia de Estado en las reivindicaciones y las luchas por la memoria" (Historia 14). 
en la literatura testimonial que, entonces, admite su caracterización como postdictatorial ${ }^{11}$.

Dentro del amplio corpus de testimonios literarios producidos a partir de 1983, es posible identificar tres líneas narrativas básicas. En primer lugar, encontramos los relatos sobre la dictadura militar, en que el protagonista del testimonio se presenta como sobreviviente y/o testigo del terrorismo estatal (Nofal, La escritura 39; Strejilevich 4-5; Goicochea 77). Son ejemplos de este conjunto: Recuerdo de la muerte de Miguel Bonasso (1984), La Escuelita. Relatos testimoniales de Alicia Partnoy (2006 [1986]), Pasos bajo el agua de Alicia Kozameh (1987) y Una sola muerte numerosa de Nora Strejilevich (2005). En segundo lugar, surgen los relatos sobre la vida política de las izquierdas en los años 60-70, en los cuales el testimonio se asocia a la narración de las experiencias de militancia, sobre todo las vinculadas a las organizaciones armadas (Nofal, La escritura 36; Strejilevich 68; Pittaluga). Son expresiones de esta serie Los compañeros de Rolo Diez (2000 [1986]) y La voluntad. Una historia de la militancia revolucionaria en la Argentina de Eduardo Anguita y Martín Caparrós (1997-1998). En tercer lugar, aparecen los relatos de hijos de víctimas o sobrevivientes de la represión durante la dictadura, en los que el testimonio vehiculiza la reconstrucción de las identidades damnificadas y usurpadas por el poder dictatorial, pero además comporta una reflexión crítica sobre el legado político de la generación militante de los años setenta (cfr. Logie y Nofal, "La guardarropía"). Dentro de este grupo se ubican La casa de los conejos de Laura Alcoba (2008 [2007]) y el Diario de una princesa montonera de Mariana Eva Perez (2012).

Notemos que la identificación de tres series diferenciadas de literatura testimonial argentina postdictatorial conlleva una periodización de dicho corpus. En efecto, fue la denuncia sobre el accionar terrorista del régimen dictatorial lo que predominó en los testimonios literarios de los primeros años de la transición democrática, mientras que el auge de la producción testimonial sobre las militancias setentistas se constata solo a partir de la mitad de la década de 1990. En tanto, las narrativas ligadas a la generación posterior a la de quienes protagonizaron el proceso de los años 70 -como militantes y/o destinatarios de la represión dictatorial-se expanden a partir de la década de

11 Siguiendo a Avelar (29) y a Dalmaroni (124), la noción de postdictadura no designa un lapso temporal sino una matriz de comprensión cultural, ligada a las resonancias contemporáneas del proceso histórico de los años 70 . 
$2000^{12}$. Observemos, además, que los textos que hemos presentado, como panorama de la literatura testimonial argentina contemporánea, no agotan el conjunto de testimonios producidos en la Argentina sobre el proceso histórico de los años 70. Dentro de ese conjunto amplio de producciones testimoniales, nos referimos específicamente a textos que, debido a ciertos rasgos discursivos, pueden ser considerados como literatura testimonial. Se trata, así, de obras narrativas que, por un lado, presentan un aspecto testimonial y/o documental: despliegan relatos de hechos reales -esto es, se inscriben en el ámbito discurso factual- ${ }^{13}, \mathrm{y}$ validan el carácter verídico que postulan para sí apelando ya a la palabra de uno o más testigos -quienes han estado $a h i^{-}$, ya a piezas de discurso escrito sobre las cuales se supone que aportan datos fidedignos acerca de los sucesos narrados y que, por lo tanto, prueban su veracidad. Por otro lado, los textos que consideramos para el análisis combinan su aspecto testimonial-documental con características del discurso ficcional y/o del discurso poético: no se trata simplemente de discursos de denuncia sino de testimonios literarios, escritos con pretensiones estéticas e insertos dentro de proyectos de escritor particulares ${ }^{14}$.

12 Los períodos de la literatura testimonial posdictatorial que aquí distinguimos coinciden históricamente, a grandes rasgos, con las etapas que se han identificado en la literatura sobre la dictadura, por un lado (Dalmaroni 155 y ss.), y en la producción testimonial sobre el pasado reciente, por otro (Pittaluga 125 y ss.).

13 Según Jean-Marie Schaeffer, el discurso factual se opone al ficcional: mientras que el primero se define como tal según criterios semánticos $\mathrm{y}$, por lo tanto, es o bien verdadero o bien falso, el segundo responde a criterios pragmáticos: instaura un pacto intersubjetivo de fingimiento lúdico, en cuyo marco la verdad y la falsedad de las proposiciones resultan irrelevantes ("Fictional vs. factual narration").

$14 \mathrm{Si}$, como lo señala Anna Forné, la mayoría de los estudios sobre el testimonio "privilegian el contenido por encima de la forma" (217), nuestra aproximación al género pondera su dimensión literaria. En esta línea, hemos formulado en otros trabajos los fundamentos conceptuales del enfoque del género testimonial que aquí presentamos sucintamente, y cuyas implicaciones complejas atañen a los criterios de construcción del corpus, al método de análisis y, más todavía, a una teoría del discurso literario (García, "Testimonio literario" y"Testimonio y literatura" 12-20). 


\section{LITERATURA TESTIMONIAL ARGENTINA POSTDICTATORIAL: LOS RELATOS DEL SOBREVIVIENTE-TESTIGO}

Consideraremos a continuación la primera de las series de la literatura testimonial argentina postdictatorial que hemos identificado en la Introducción, esto es, la de los relatos ligados al sobreviviente-testigo del terrorismo de Estado. Particularmente, abordaremos tres textos que ya hemos mencionado, escritos durante la década de 1980: Recuerdo de la muerte de Miguel Bonasso, La Escuelita de Alicia Partnoy y Pasos bajo el agua de Alicia Kozameh ${ }^{15}$. El estudio contrastivo de estas tres obras resulta productivo en la medida en que permite observar estrategias narrativas distintas adoptadas en relación con la experiencia de detención clandestina y resistencia al terrorismo estatal, que comparten sus protagonistas. En efecto, los significados que cada relato atribuye a dicha experiencia no se desprenden solo del contenido narrativo -es decir, de los hechos que componen la historia- sino, sobre todo, se asocian a la forma literaria que presentan los textos. En esta línea, cobra importancia una cuestión que ha recibido escasa atención específica por parte de la crítica: en particular, los modos de articulación entre testimonio y ficción, que intervienen en la construcción de los relatos sobre la experiencia concentracionaria. Como podremos ver, si por un lado los textos testimoniales que analizaremos no pueden caracterizarse sin considerar su condición de narraciones de hechos reales, por otro lado recurren al discurso ficcional -y, en cierto sentido, hasta son ficción-, en la medida en que dicha forma narrativa colabora a la representación de las características complejas de la experiencia concentracionaria. Así, si dar testimonio de esa experiencia suele constituir una necesidad imperiosa para los sobrevivientes-testigos (Jelin 111), asimismo la ficción resultará vital en la puesta en palabras del relato testimonial.

15 Luego de su publicación original en los años 80, los tres libros fueron reeditados con modificaciones en los textos implementadas por sus autores (Strejilevich 28, Longoni 62, Simón). Para el análisis, utilizamos las primeras ediciones de Recuerdo de la muerte y Pasos bajo el agua. En el caso de La Escuelita, tomamos como fuente básica la edición argentina de 2006, debido a que la edición en inglés de 1986 no tiene circulación en la Argentina, y considerando que el castellano fue la lengua original del texto, sobre el cual Partnoy luego realizó una autotraducción. Según señala Paula Simón, "[1]a primera edición argentina, llevada a cabo en 2006 por la editorial La Bohemia, se mantiene fiel al manuscrito de 1983, previo a la edición en lengua inglesa" (37). 


\section{RECUERDO DE LA MUERTE: LA "NOVELA TOTAL" SOBRE LA DICTADURA}

La serie de testimonios literarios de sobrevivientes del terrorismo de Estado se inicia con Recuerdo de la muerte, de Miguel Bonasso, aparecido en 1984 en la Argentina y en México - escenario de la escritura y del exilio del autor- (Pozzoni 27). El libro cuenta la historia de Jaime Dri en la dictadura, que comienza con su secuestro en 1977 y culmina con su fuga del centro clandestino de detención, tortura y exterminio que funcionaba en la Escuela de Mecánica de la Armada ${ }^{16}$. La historia de supervivencia de Dri narrada en el libro de Bonasso no deja de ser, al mismo tiempo, la de su militancia en Montoneros en el período dictatorial, militancia que el exdetenido compartió con el autor del libro ${ }^{17}$. En efecto, como lo ha señalado Longoni (81), el protagonista de Recuerdo de la muerte aparece como el "héroe" que logra fugarse de la ESMA debido a una solidez ético-política que lo diferencia de los "traidores" con los que se encuentra en su camino: aquellos que habían sido militantes montoneros como Dri, pero que como detenidos se "quiebran" -colaboran con los represores, suministrando información que estos exigían bajo tortura, para la captura de más compañeros-.

La épica militante que atraviesa el relato de Bonasso sobre la experiencia de detención clandestina de Dri, coloca al texto en continuidad con la dimensión militante de la literatura testimonial de los años 60-70. No obstante -y paradójicamente- el libro se escribe partiendo de la asunción de un fin de época y, con mayor precisión, surge como respuesta a los interrogantes profundos que plantea, ya en democracia, dejar atrás los politizados setentas. En las palabras del autor, un problema crucial luego de la dictadura será "cómo dar por superada una etapa, una determinada concepción, sin convertirse en

16 Entre el 15 de diciembre de 1977 y el 19 de julio de 1978, Dri estuvo prisionero en la ESMA, en la Quinta de Funes, en la Escuela Magnasco, en La Intermedia y, por último, nuevamente en la ESMA. Para un relato testimonial del propio Dri sobre su secuestro, detención y fuga, véase su declaración como miembro del Consejo Superior de Montoneros, datada en septiembre de 1978.

17 Montoneros fue una organización guerrillera peronista conformada en 1970, que constituyó uno de los blancos centrales de la represión desplegada por el gobierno dictatorial a partir de 1976 (Calveiro, Política y/o violencia 74-85). En marzo de 1980, Miguel Bonasso y Jaime Dri fueron expulsados de la organización y fundaron el "Movimiento 17 de Octubre" (Pozzoni 28). 
renegados" $(405)^{18}$. La reconstrucción del pasado constituye un elemento ineludible del proceso complejo que implica dicho cambio de época. Por eso, Recuerdo de la muerte se presenta como "un libro contra el olvido" (404). Por eso, también, la historia de resistencia de Dri aparece como representativa de todo un proceso histórico argentino: según lo expresa Bonasso, se trata de "Un segmento en la vida de un hombre y un pueblo" (397).

Los principios orientadores de la escritura de Recuerdo de la muerte se explicitan en la "Crónica final", postfacio que funciona como declaración de intenciones políticas y literarias del autor. Allí, Bonasso caracteriza al libro como una "novela-real o realidad-novelada" (397) centrada, no obstante, en un hecho "rigurosamente cierto", y apoyada en "una base documental enorme y concluyente" sobre los sucesos narrados (404). Según el autor, su opción por el género novelístico adquiere fundamento en el hecho de que "La novela permite desenterrar ciertos arcanos que a veces se niegan a salir dentro de las pautas más racionales de la crónica histórica, el testimonio de denuncia o el documento político" (404). A la vez, Bonasso sostiene que "la voluntad de novelar no encubre [...] el designio de modificar los hechos" (404). Formulado en esos términos, el pacto de lectura propuesto por Recuerdo de la muerte es ambiguo y complejo (Longoni 55-60), pues se apoya en convenciones propias de dos tipos discursivos aparentemente opuestos: la ficción y el discurso factual. La misma ambigüedad se constata al analizar las estrategias narrativas a las que Bonasso efectivamente recurre en el texto para dar cuenta de la historia de Dri en la ESMA.

Así, por una parte, la idea de una "novela-real" afirmada en la "Crónica final" remite al carácter en cierto sentido novelesco que Recuerdo de la muerte atribuye a la experiencia del terrorismo de Estado atravesada por Dri. En efecto, son frecuentes en el texto las descripciones de la vida en el centro clandestino de detención como experiencia cercana a la ficción: "alucinación colectiva" (93) o "reino de los espectros" (63), que difumina las fronteras

18 Si consideramos al texto dentro del grupo de testimonios referidos al terrorismo de Estado, y no dentro de la serie de testimonios sobre la militancia setentista, es porque la dictadura constituye en Recuerdo de la muerte una condición básica de producción del relato: el militante ejemplar personificado por Dri cobra sentido como resistente y sobreviviente a la violencia de Estado. En esa línea, Recuerdo de la muerte integra una serie de relatos sobre el pasado reciente en los cuales, como señala Pitttaluga, "el tema de la militancia aparecía como telón de fondo $[\ldots]$ de unas escrituras cuya característica principal era la de [...] intervenciones orientadas a registrar la violencia del terrorismo de Estado" (130). 
entre vivos y muertos. De esta manera, los sucesos ligados a la detención clandestina tienden a aparecer como ajenos a los parámetros de verosimilitud de la realidad histórica argentina conocida hasta el autodenominado "Proceso". En ese marco, la historia de la fuga de Dri constituye un caso límite de lo inverosímil: "Si yo estuviera en el lugar de ellos, me costaría creer en una fuga tan inverosímil como la mía", comenta el protagonista en la "Crónica final" (399), especulando sobre la escasa audibilidad de que su testimonio gozaría frente a quienes no han atravesado la experiencia concentracionaria -incluso sus propios compañeros de militancia- (Jelin 112).

Por otra parte, la noción de "realidad- novelada" a la que Bonasso apela en la "Crónica final" reenvía a la "forma novelística" (404) que el autor adopta para narrar la historia. Efectivamente, Bonasso despliega procedimientos narrativos de la ficción para contar la historia del "Pelado" Dri. La estrategia básica es la de un narrador heterodiegético, que cuenta los hechos desde afuera, a un punto tal que, en ciertos momentos del relato, el propio Bonasso aparece señalado en tercera persona, como uno de los personajes (véanse los capítulos "Operación México" y "El tiro por la culata"). El narrador se focaliza en la figura de Dri, cuya historia organiza la trama, y tiende a identificarse con él. Así, el relato diluye la distancia entre la voz del narrador y la del personaje, mediante el recurso al monólogo interior y al discurso indirecto libre ${ }^{19}$. Notemos, no obstante, que el relato básico sobre el secuestro, la detención y la fuga de Dri se complementa en la novela con episodios narrativos focalizados en otros militantes capturados por el dispositivo represivo -incluso quienes han muerto y no pueden testimoniar sobre su propia historia-, y en los mismos represores, que por momentos aparecen como protagonistas del relato (Foster, Violence 37; Strejilevich 91) ${ }^{20}$.

19 Mencionemos solo un ejemplo del capítulo "El traslado", donde es clara la identificación del narrador con la figura de Dri: "Recordó entonces la palabra: desaparecido. Alguien que flota entre la vida y la muerte. La muerte que se le había presentado de tan distintas maneras durante su vida. La muerte de su padre. Las primeras muertes de la gente que uno había pensado que no se iba a morir nunca" (43, nuestro subrayado).

$20 \quad$ Significativamente, los procedimientos de focalización interna se emplean también en relación con los represores (Foster, Violence 37). Así ocurre, por ejemplo, en el siguiente pasaje sobre el Tigre Acosta: “¿Qué quiere que hagamos? -se interrogaba- ¿Que fusilemos a todos los peronistas? No, la cosa no va por ahí. Hay que darle leña a los subversivos y después...' Ese después siempre era impreciso. Uno no sabía muy bien a cuántos exactamente había que fusilar y qué haría el resto" (65, nuestro subrayado). En este caso, la identificación 
De este modo, considerada globalmente, Recuerdo de la muerte toma la forma de un relato novelesco con narrador omnisciente, un relato que parece contarlo todo sobre los hechos reales que constituyen su objeto (Longoni 64). En este sentido, el texto de Bonasso construye un singular efecto de realidad como discurso narrativo: no solo ostenta, debido a las estrategias narrativas que despliega, la pretensión de verosimilitud propia de la ficción realista, sino además busca instaurar el carácter verídico del relato pues, como señalamos, su complejo pacto de lectura interpela a interpretar la novela en clave de discurso factual.

En efecto, al mismo tiempo que Bonasso escribe sobre hechos "novelescos" en tanto históricamente extraordinarios, y apela al género novelístico como forma narrativa del texto, el autor declara, como señalamos, la estricta verdad de su narración, vinculada a su apoyo en una sólida prueba documental. Se trata, en rigor, de tres tipos de "prueba". En primer lugar, se observan intercalaciones documentales en zonas puntuales del relato: transcripciones de documentos políticos de Montoneros (207, 217, 222), facsímiles de notas periodísticas $(203,209)$ y, en el capítulo "Testimonios", declaraciones de sobrevivientes ante distintos organismos internacionales de derechos humanos (115 y ss.). En segundo lugar, el autor, que como ya vimos aparece como personaje en ciertos pasajes del relato, en otros momentos se presenta en la narración como un yo que se identifica como escritor y, por eso, remite al enunciador real de la "Crónica final": "Perdón por meterme [...]. Este capítulo es uno de los que me han dado más trabajo [...]. Revolviendo el magro archivo reaparecen los muertos de 'allá lejos' y los viejos de 'hace tiempo' [...]. No todas las imágenes ayudan a recordar con precisión. A veces no recuerdo [...] en qué momento fueron tomadas" (359), comenta el narrador en el capítulo "Lejanías". Los pasajes momentáneos a un relato homodiegético buscan, así, reafirmar el rol de Bonasso en la reconstrucción de la historia, pero también su participación en los hechos narrados. En tercer lugar, y centralmente, es el testimonio de Jaime Dri que aparece como prueba del carácter verídico del relato. En esa línea, el autor afirma en la "Crónica final" que la elaboración del libro fue posible por la disposición del testigo a que el escritor practicase "espeleología literaria en las cavidades más recónditas de su conciencia" (404). Pero subrayemos que, no obstante esta indicación autorial sobre la

del narrador con el personaje se expone ante el lector como una estrategia narrativa disociada de la postura político-ideológica del autor, evidentemente antagónica a la de los represores. 
escritura del texto -y sobre cómo habría que leerlo-, la palabra de Dri no aparece representada como testimonial en el relato, sino reelaborada y, en rigor, invisibilizada bajo un dispositivo narrativo configurado con los códigos del discurso ficcional.

Considerada en su conjunto, entonces, Recuerdo de la muerte integra ficción y discurso factual, tanto en las indicaciones autoriales que guían la lectura, como en los procedimientos narrativos efectivamente desplegados en el relato. La ambivalencia genérica del libro permite analizar la relación compleja que, como ejemplar de la literatura testimonial argentina en la transición democrática, establece con la historia nacional del período dictatorial. En ese sentido, ciertas opciones literarias y políticas de Bonasso, que quedan expuestas en la materialidad textual, cuestionan las intenciones del autor declaradas en la "Crónica final". En efecto, el hecho de que el escritor se haya propuesto elaborar un relato "rigurosamente cierto" sobre Jaime Dri, como "segmento en la vida de un hombre y un pueblo", no deja de entrar en tensión con la forma que eligió para el texto: un relato novelesco con pretensiones realistas, pero basado centralmente en la versión de Jaime Dri sobre los hechos. Consideremos que Dri fue el único de los detenidos en la ESMA que se fugó del cautiverio y sobrevivió a la represión. Sería posible pensar, pues, que la faceta inverosímil del relato sobre el "Pelado" Dri, a la que nos referíamos más arriba, no solo se vincula a la experiencia históricamente inusitada que atravesaron las víctimas del terrorismo estatal, sino además va asociada al episodio extraordinario que representó su fuga y, con ello, a un limitado alcance representativo respecto de la experiencia de las víctimas del terror dictatorial ${ }^{21}$. En efecto, otros sobrevivientes de la ESMA que discutieron el contenido del libro con Bonasso, antes de que se publicara, desconfiaron de la veracidad del relato sobre la detención clandestina que allí se desarrollaba -como lo admitirá, años después, el propio Bonasso-22.

21 Longoni ha cuestionado la representatividad de la historia de Dri narrada en Recuerdo de la muerte: para ella, a Bonasso "le basta contar exclusivamente con el testimonio de Dri para habilitarse como observador de los laberintos de la ESMA y de Funes"; el escritor "eligió ceñirse a una verdad única y por eso mismo estrecha" (64). En el mismo sentido, la autora repara en la faceta individualista del Dri de la novela, que es la contracara de su supuesto heroísmo excepcional: "nunca abandona sus intenciones de fugarse por su cuenta, y finalmente lo consigue, poniendo en mayor riesgo a aquellos que continuaban prisioneros" (109).

22 Bonasso menciona los debates que él y Dri mantuvieron con otros sobrevivientes de la ESMA, previamente a la publicación del libro, en el postfacio "Paredón y después", añadido a la Edición definitiva del libro, de 1994: "Tuvimos varios encontronazos con varios 
Desde esta perspectiva, Recuerdo de la muerte tomaría forma novelesca no solo para volver los hechos narrables, develando los "arcanos" o aspectos recónditos de la realidad del terrorismo de Estado, como el autor lo plantea en la "Crónica Final". Más bien, el recurso a la ficción en el libro de Bonasso iría asociado al desfase entre el relato de supervivencia heroica que allí se propone y la compleja realidad de la detención clandestina, que surge al confrontar la novela de Bonasso con relatos testimoniales de sobrevivientes del terrorismo estatal ${ }^{23}$.

Ahora bien: al mismo tiempo, resulta innegable que en Recuerdo de la muerte la ficción efectivamente permitió dar cuenta de ciertos sucesos ligados al poder concentracionario de la dictadura, en los inicios de la transición democrática. De hecho, el libro apareció en marzo de 1984, antes incluso que la recopilación de testimonios de sobrevivientes que constituyó el Nunca más. En la misma línea, no es posible dejar de lado el hecho de que la forma novelada del libro de Bonasso otorga al relato la capacidad característica de la ficción, de propiciar la inmersión del lector en la historia narrada ${ }^{24}$. En efecto, significativamente, para 1988 Recuerdo de la muerte contaba con tres reediciones en la Argentina. Desde este punto de vista, la extensa difusión que alcanzó el texto de Bonasso no dejaría de mostrar la eficacia narrativa del recurso a la ficción novelesca, en la denuncia del autor sobre el dispositivo represivo implementado por el gobierno dictatorial ${ }^{25}$.

sobreviviventes de la ESMA. En general, salvo excepciones, seguían sin perdonarle a Jaime que se hubiera escapado" (466). Dos décadas más tarde, en Lo que no dije en Recuerdo de la muerte, el escritor agrega detalles sobre aquellos debates. En particular, apunta críticas que recibió como autor, relacionadas con la forma novelesca que dio al libro, con su "presunta herejía de convertir en héroe a Jaime Feliciano Dri”, así como con la perspectiva ideológica que imprimió al relato sobre los vínculos íntimos entre prisioneras y represores (27).

${ }_{23}$ Ya en los años 80, el mismo Jaime Dri incorporaba a su relato testimonial la complejidad de la experiencia de la detención clandestina, cuestionando la lógica de traidores y héroes que sostiene Bonasso. Así, sobre la colaboración de algunos detenidos con los represores, el sobreviviente afirmó en 1984: "no se puede juzgar con severidad la conducta de ninguna persona colocada en una situación tan límite como la que han pasado los secuestrados" (cit. en Longoni 115).

24 Tomamos la noción de inmersión ficcional de Jean-Marie Schaeffer, quien sostiene que, desde el punto de vista del lector, esta implica "dejarse atrapar, deslizarse en los ganchos creados por el creador" (Por qué 179).

25 Una paradoja similar está presente en Operación masacre, de Walsh. En efecto, el texto debe su potencial literario, ligado a su forma novelesca, a una perspectiva política sobre los hechos que originalmente desdibujaba el sentido histórico de la represión al levantamiento 


\section{LA ESCUELITA, EXTRAÑAMIENTO Y RECREACIÓN FICCIONAL}

La Escuelita, publicado originalmente en el exilio de Partnoy en los Estados Unidos, en 1986, y editado en la Argentina solo veinte años más tarde, narra la experiencia de la autora en el centro clandestino de detención "La Escuelita" de Bahía Blanca, donde Partnoy estuvo prisionera entre enero y junio de 1977. El libro combina un anclaje testimonial explícito, desplegado en el relato autobiográfico de la "Introducción" y en los fragmentos de declaraciones judiciales de los Anexos, con modalidades narrativas propias del discurso ficcional. La impronta testimonial del texto de Partnoy se asocia a la responsabilidad asumida por la autora, en tanto sobreviviente, de contar lo vivido y visto: "Como sobreviviente, sentí que era mi deber ayudar y dar testimonio" (13), afirma en la "Introducción". Partnoy presenta su relato como fragmento de un proceso histórico que no solo es argentino sino, más ampliamente, latinoamericano, y que, por lo tanto, excede su acotada experiencia como testigo: "Conocí sólo una Escuelita, sin embargo, en nuestro continente hay muchas 'escuelas' cuyos maestros se especializan en enseñar a perder la memoria y la convicción ideológica a fuerza de torturas y humillaciones" (15, nuestro subrayado). De esta manera, la autora reconoce la condición inacabada de su relato testimonial (Sarlo, Tiempo pasado 72) ${ }^{26}$.

En cuanto a la faceta ficcional de La Escuelita, esta remite a la forma que la escritora elige para dar su testimonio, forma que se anuncia en la indicación genérica incluida en el subtítulo original del libro: Tales of Disappearance and Survival. Resulta significativa la intertextualidad que Partnoy establece con la clásica compilación de relatos de Poe, Tales of Mystery and Imagination, no solo porque se trata de una referencia cultural fácilmente reconocible para los lectores estadounidenses a quienes se destinó inicialmente el libro, sino

de Valle y que, por eso, el propio autor eventualmente consideraría como desatinada (cfr. García, "Testimonio y literatura" 20-24).

26 "El testimonio", señala Pilar Calveiro en este sentido, "realiza un relato preciso, el de la propia experiencia, y al hacerlo fija de manera explícita sus límites. Parte invariablemente de la identificación del sujeto que enuncia, así como de la precisión de las coordenadas de tiempo y lugar en las que ocurrió la experiencia, lo que permite acotarlo de inmediato" ("Testimonio y memoria" 77). Notemos que, en los Anexos, Partnoy vuelve a expresar el carácter limitado e incompleto de su testimonio: al enumerar a los represores del centro clandestino de detención, menciona a "cinco más cuyo alias no recuerdo" (113); sobre la lista de detenidos en la Escuelita, afirma que: "Los posibles errores u omisiones se deben al desconocimiento de la testimoniante en el momento de presentar el informe" (118). 
además porque se subraya de este modo la dimensión ficcional de la serie de relatos. En efecto, para 1986 y en Estados Unidos, los sucesos ligados al terrorismo de Estado argentino podían aparecer como "ficciones", esto es, como hechos inverosímiles dentro de los parámetros de la propia realidad histórica. Por eso, la autora afirma en la "Introducción" que en los centros clandestinos de detención donde se desarrollan sus relatos "los límites entre la historia y las historias [story and history] son tan tenues que ni yo misma los puedo detectar" $(15)^{27}$. En este punto, el fundamento del recurso a la ficción en La Escuelita resulta similar al de la "novela real" ideada por Bonasso; no obstante, las características discursivas que adopta la articulación entre testimonio y ficción, y los efectos de sentido que resultan de ello, son diferentes en cada caso.

Así, desde el punto de vista de los procedimientos narrativos que configuran el texto, La Escuelita no presenta una forma homogénea. El narrador protagonista, identificable con una primera persona testimonial, predomina en los relatos y reafirma, así, el pacto de lectura establecido en los paratextos del libro. Sin embargo, la enunciación testimonial no caracteriza a la serie narrativa en su totalidad. Por momentos, un narrador heterodiegético toma a su cargo el relato, incluso cuando se trata de circunstancias protagonizadas por la propia Partnoy. Así ocurre en "Chancletas con una sola flor" (21), centrado en el secuestro de la autora. En otras zonas del libro, en tanto, se recurre a un narrador protagonista que no remite a Partnoy sino a sus compañeros detenidos. Esta estrategia narrativa expone el intento de la autora por rescatar, a través de su testimonio, la experiencia de todos los que fueron víctimas de la represión en "la Escuelita". A la vez, permite representar la voz de quienes no sobrevivieron al centro clandestino de detención y que por ende, fuera de la recreación ficcional, no pueden tomar la palabra (Salomone 187) ${ }^{28}$. Así sucede, por ejemplo, en el relato "Natividad", centrado en el parto de la prisionera Graciela, posteriormente asesinada $(103)^{29}$.

27 Observemos que, en la primera edición del texto, la escritura de la "Introducción" se sitúa explícitamente en el contexto estadounidense: "Washington D.C. December 1985", firma la autora al final del prefacio (18).

28 Retomamos en este punto la idea de Agamben de que el testimonio lleva inscripta la lengua "del testigo integral, la del que no puede prestar testimonio" y, por eso, presenta un inevitable carácter lacunar (39).

$29 \quad$ Según Partnoy ha declarado en entrevistas sobre su obra, buscó representar las voces de otros prisioneros para enfatizar el carácter compartido de la experiencia sobre la cual da 
En su conjunto, los relatos de La Escuelita consisten en pequeñas escenas que dan cuenta de la vida en el centro clandestino de detención. En la pequeñez de dichas escenas se expone la aparente insignificancia de sucesos que, sin embargo, resultan cruciales para la resistencia y la supervivencia de los detenidos (Sarlo, Tiempo pasado 72). En efecto, la experiencia del cautiverio parece propiciar el extrañamiento sobre las cosas de la vida tal como se aparecen fuera de la detención clandestina, extrañamiento que constituye una precondición de la escritura literaria. Así se observa, por ejemplo, en "La cajita de fósforos" de uno de los relatos -"La cajita de fósforos es mi única posesión [...]. A cada rato la toco para asegurarme de que sigue allí" (74)-, o en la "Conversación bajo la lluvia" que mantienen dos prisioneras en otra de las narraciones -"a pesar de los golpes y las prohibiciones, a pesar de la mugre y la tortura, ellas dos habían tenido aquella larga y tibia conversación bajo la lluvia" (62)-. Se trata de objetos o situaciones que, si en la vida fuera del centro de detención resultan naturales, prescindibles o incluso triviales, se vuelven importantes para resistir dentro de la experiencia inhumana del cautiverio concentracionario: "Ahora que gracias a ella puedo ver, las cosas han cambiado. Sin embargo, desde que tengo memoria siempre renegué de mi nariz [...]. Lo que ocurre es que su forma mantiene la venda de mis ojos ligeramente levantada" (51-52), cuenta la narradora en el relato "Nariz", exponiendo así los límites de su campo visual como testigo y, con ello, los alcances acotados de su haber estado allí.

En esa línea, si La Escuelita cuenta cómo las cosas pequeñas y hasta insignificantes de la vida pasan a resultar vitales para los detenidos, a la vez sugiere la ironía que ello constituye y, más aún, denuncia la absurdidad injusta de la experiencia concentracionaria narrada en el libro (Strejilevich 84-85, Salomone 183-184). "Esa flor, entre la mugre y el miedo, los gritos y la tortura, esa flor tan de plástico [...] era casi obscena, absurda, una burla..." (23-24), afirma el narrador de "Chancletas con una sola flor" sobre un objeto al que, no obstante, se aferra el personaje durante su reclusión. Es que, en efecto, la extrañeza de la vida que surge con el cautiverio puede llevar a la pérdida de la propia identidad o a la desmemoria, y es frente a ese sinsentido que resisten los prisioneros: "Hace rato que estoy tratando de recordar cómo es la cara de Ruth" (65), cuenta la narradora sobre su hija en el relato

testimonio: "[my] first goal was to tell the stories of the others because [I] was the survivor, and $[\mathrm{I}]$ wanted to stress the collective" (cit. en Betterman 44). 
"Rompecabezas", mientras que el Benja, en otro relato, se rehúsa a perder sus señas identitarias básicas, simbolizadas en el nombre: "El nombre... mi nombre, ya me olvidé de mi nombre [...]. No importa [...]. Mi edad no me la olvidé [...]. Tampoco me olvidé que soy peronista, montonero, ni que hice todo lo que pude contra estos milicos que nos están... pero eso no se lo dije a ellos" (37). Finalmente, el relato "Nombre" condensa el gesto de resistencia que La Escuelita representa frente a la violencia del discurso y las prácticas dictatoriales: "En la Escuelita no tengo apellido [...]. Me llaman 'La Muerte'. Será tal vez por eso que cada día repito para mis adentros que yo, Alicia Partnoy, todavía estoy viva" (36). Se trata, entonces, de resistir en y por el acto de la palabra, pues el yo-testigo de La Escuelita, que habla una vez que ha finalizado la captura de Partnoy, no deja de remitir al arte verbal que el personaje de la prisionera practica en los relatos para resistir al poder concentracionario - especialmente, en "Cepillo de dientes" (68) y "Poesía" (89), que tematizan la creación poética durante la detención clandestina-.

Así pues, el recurso a la ficción en La Escuelita expone el carácter inseparable de las figuras de escritora y testigo al que responde la escritura del texto. El testimonio de Partnoy se conforma como serie de cuentos no solo porque el potencial liberador de la creación literaria fue importante para la resistencia de la autora durante su cautiverio, sino además -y sobre todo- porque en las pequeñas piezas narrativas tiene lugar la singularidad de la experiencia concentracionaria -ligada a la percepción extrañada de la vida que surge en la detención clandestina-, así como la condición fragmentaria que la autora adjudica a su relato testimonial sobre el terrorismo de Estado.

\section{LA FICCIÓN COMO SÍMBOLO EN PASOS BAJO EL AGUA}

Pasos bajo el agua de Alicia Kozameh, publicado en la Argentina un año después de la edición estadounidense de La Escuelita, cuenta el secuestro de la autora por las fuerzas parapoliciales de la Triple A en 1975, y su cautiverio que comenzó en el centro clandestino de detención "el Sótano" de Rosario, y continuó en el penal de Villa Devoto hasta 1978 (Boccanera 11, Sillato 48). El libro comparte con el relato testimonial de Partnoy su carácter fragmentario, pero también la remisión indirecta, mediada por la ficción, a una experiencia vivida por quien escribe. Más aun, acentúa la dimensión ficcional del relato testimonial. 
Así, como Partnoy, Kozameh da inicio al texto declarando en el prólogo su objetivo como testimonio, pero enunciando, además, un propósito literario: "Estos relatos fueron escritos para que los episodios de los que me ocupo sean conocidos. Les he dado forma literaria porque me gusta, disfruto trabajar aprendiendo la literatura. Lo sustancial de cada uno es verdadero, sucedió [...], aunque he reemplazado nombres o quizá detalles que para nada cambian, de hecho, la esencia de la cosa" (7, nuestro subrayado). Kozameh explicita, de esta manera, el sustento verdadero del libro y su faceta literaria: más precisamente, su dimensión inventiva e incluso ficcional. En efecto, Pasos bajo el agua consiste en una serie de relatos sobre la prisión de un mismo personaje, Sara, en "el sótano" de Rosario. El hecho de que la historia del personaje remite a la vivencia de la propia autora queda expuesto en el texto debido a la identidad referencial manifiesta entre el testimonio del prólogo, donde Kozameh se presenta como exdetenida del "sótano" (7), y los hechos protagonizados por Sara.

Asimismo, las estrategias narrativas desplegadas en los relatos tienden a disolver la distinción entre la voz del personaje de Sara, la de la propia autora y la del narrador heterodiegético, que predomina en la serie narrativa. Por un lado, el narrador toma por momentos la voz del personaje de Sara, mediante el recurso al discurso indirecto libre, tal como se observa desde el cierre del primero de los textos, "A modo de regreso": "Sara va bajando detrás de $s u$ padre, con esa lentitud a la que obligan escalones cubiertos de gatos amontonados [...]. La cárcel no deja tiempo para ocuparse de los gatos [...]. Para mi padre un gato es un gato. Para mí hoy es una mueca reverencial que me hace la libertad. Hacerse cargo" (15, nuestro subrayado). La misma fusión entre el discurso del narrador y el del personaje es observable en otros relatos: "Los hechos. Las zanjas", "Adriana recibe visitas" y "Sandalias, Ernesto, lágrimas y té". Por otro lado, en "Carta a Aubervilliers" y "Del diario de Sara”, el narrador delega el relato en el personaje. Sara, así, aparece como autora ficticia de la carta y del diario carcelario que dan forma a los episodios narrativos. Finalmente, en el último de los cuentos, "A modo de regreso II", el narrador pasa a ser homodiegético -protagonista-, y sugiere su identificación con Sara y con la escritora de Pasos bajo el agua: "Tres pasos bajo el agua: bueno para un título, si estuviera escribiendo algo" (101); "Vamos. Que el aire entre. [...] Eso me decía a mí misma camino a los gatos" (106). De esta manera, el personaje de Sara, que en el final del libro llega a 
situarse como narradora y escritora de su propia historia, reenvía a la primera persona testimonial que, en el paratexto inicial, enmarca los relatos ${ }^{30}$.

El juego de distancias y aproximaciones enunciativas entre Sara, como creación ficticia, y la autora, como testimoniante, expone la relación singular entre discurso ficcional y factual, o entre literatura y testimonio, que practica Pasos bajo el agua. En efecto, el libro, como relato sobre la prisión política y el terrorismo estatal en la Argentina, representa no solo la vivencia personal de Kozameh, sino la de todas aquellas mujeres o "Saras" que atravesaron dicha experiencia social. Lo indica la escritora en el prólogo: "lo viví yo misma $o$ lo vivieron otras compañeras y yo lo supe" (7, nuestro subrayado). Así, es el intento de Kozameh por dar cuenta de una experiencia no individual sino compartida lo que vuelve irrelevante la diferenciación entre el testimonio de quien escribe y el de otras víctimas de la represión, y, correlativamente, también torna inestables los límites entre las distintas voces que habitan el relato testimonial.

No obstante, al mismo tiempo que Pasos bajo el agua remite por medio de la historia de Sara a múltiples experiencias individuales de la detención clandestina, no da cuenta, en rigor, de ninguna experiencia real, puesto que Sara no deja de ser una figura inventada. En este sentido, el texto de Kozameh ostenta como testimonio concentracionario una representatividad singular, apoyada menos en la fidelidad del relato a ciertos hechos postulados como verídicos, que en el valor simbólico que la ficción protagonizada por Sara adquiere respecto de su referente histórico. El personaje de Sara surge, en efecto, de una condensación simbólica que alude, sin describirla directamente, a la experiencia de las víctimas de la represión estatal ${ }^{31}$. Este procedimiento

30 Acerca de la identificación entre Sara y la autora a partir de la escritura literaria, notemos que los relatos tematizan la creación poética que Sara lleva adelante durante su prisión $(37,41)$-análogamente a lo que ocurre en La Escuelita, de Partnoy-. De hecho, Kozameh escribió poesía durante su cautiverio, que luego reunió en sus Cuadernos de la cárcel. Para un estudio sobre la poesía carcelaria de Kozameh, véase el trabajo de Guillard.

31 En este sentido, resulta pertinente la observación de Astrid Erll, quien ha señalado que tanto la memoria como la literatura operan por condensación. Así, los acontecimientos del pasado se representan en la memoria en la forma de topoi, imágenes o personalidades en los que se condensa el significado del pasado; la literatura, por su parte, condensa significados en procedimientos característicos de su lenguaje, como la metáfora, la alegoría y la intertextualidad (199). Erna Pfeiffer ha analizado, en cuanto a la edición de Pasos bajo el agua de 2002, el funcionamiento de los simbolismos ligados a lo femenino y a la supervivencia, que Kozameh construye en torno de la figura del gato, central en la serie de piezas narrativas. 
de ficcionalización del testimonio en Pasos bajo el agua deriva, al menos en parte -y como ocurría en el libro de Partnoy-, de la asunción de la condición incompleta de la memoria reconstruida en el discurso testimonial. Así, si como comenta Sara como remitente-narradora de la "Carta a Aubervilliers", es "Imposible recordar la totalidad" (48), resultaría fútil o incluso desacertado pretender que el testimonio dé cuenta acabada de cierta realidad histórica. Al mismo tiempo, asumida dicha fragmentariedad, la ficcionalización constituye una condición de posibilidad del testimonio, pues interpone una distancia entre el relato y la experiencia traumática -de otro modo, quizás inenarrable- que le da lugar ${ }^{32}$.

\section{CONCLUSIONES}

A la luz del análisis realizado, resulta relevante retomar la cuestión de los orígenes del género testimonial en los comienzos de la década de 1970, que presentamos en la Introducción del artículo. Es significativo, en esa línea, que la literatura de testimonio haya surgido a partir de un rechazo a la ficción como opción narrativa legítima, propugnado por los escritores latinoamericanos que aspiraban a ser revolucionarios: "La llamada ficción cada vez va perdiendo más consistencia", sostuvo Barnet en su célebre artículo "La novela testimonio: socio-literatura" (101); mientras que Walsh afirmó en la misma época, en la entrevista que mantuvo con Piglia, que "es probable que la ficción esté llegando a su esplendoroso final" (18). Sin embargo, tal como hemos podido ver en el caso de la literatura testimonial argentina de los años 80 , no hay entre testimonio y ficción una contradicción irreconciliable, sino diálogos y tensiones que se expresan en la materialidad narrativa, y cuya indagación resulta imprescindible al estudiar los modos de representación de la realidad desplegados en los testimonios literarios.

32 La misma Kozameh ha señalado, refiriéndose a su obra, que el recurso a la ficción se asocia a una toma de distancia respecto de la experiencia dolorosa que para ella constituyó la cárcel: "Si tuviera que escribir un testimonio directo de los años dictatoriales, o de mi propia experiencia durante esa época, posiblemente lo haría aunque a costa de enfermarme severamente. La mediación de la ficción, lo que ya sabemos que es la distancia establecida por el juego/trabajo ficcional, por la idea de que los personajes no son uno mismo, me salva" (Boccanera 13). 
Así, en la literatura testimonial concentracionaria que hemos considerado, el funcionamiento de la ficción no puede caracterizarse recurriendo sencillamente a la idea de un como si lúdico que atravesaría los relatos en cuanto a su estatuto enunciativo global, pues se trata de textos que no dejan de postularse como factuales. Tampoco es posible pensar aquí a la ficción únicamente como un conjunto de técnicas narrativas que sirven de instrumento a la puesta en relato de discursos que, entonces, resultarían inequívocamente factuales: hemos visto, de hecho, la ambigüedad de los pactos de lectura asociada a textos que presentan al mismo tiempo características del testimonio y de la ficción literaria. Así pues, la ficción de los relatos testimoniales sobre los que hemos reflexionado remite, más complejamente, a formas de contar el terrorismo de Estado, que reúnen modos de ser propios del relato ficticio y del relato factual.

La complejidad de estos discursos que integran ficción y testimonio no resulta ajena a la de la experiencia social que buscan representar. En esa línea, resulta notable que la ficción se presente en los libros analizados no meramente como una serie de mecanismos narrativos, sino en su dimensión vital, inscripta en las situaciones que los prisioneros atravesaron durante la detención clandestina y, después, en el difícil proceso que implicó poner en palabras dicha experiencia traumática en la transición democrática. En efecto, el carácter vital de la ficción se expone en múltiples planos de la literatura testimonial concentracionaria. En primer lugar, la creación literaria se tematiza, en los relatos de escritoras sobrevivientes, como acto de resistencia que permite afrontar las condiciones inhumanas de la vida en cautiverio. En segundo lugar, las mismas experiencias de los sobrevivientes se viven como "ficciones", pues aparecen como inverosímiles según los parámetros de la realidad histórica argentina conocida antes de la dictadura. El estatuto extraordinario y, por ello, inverosímil atribuido a la experiencia que busca narrar la literatura concentracionaria no concierne solo a los mismos sobrevivientes, a quienes les cuesta creer lo vivido y visto, ni solo a los destinatarios argentinos de los libros estudiados, que no han pasado por la experiencia del cautiverio y que, para la década de 1980, conocen poco sobre aquella realidad. Además, atañe a los destinatarios extranjeros de estos textos, pues en ciertos casos fueron publicados en los sitios del exilio de los escritores, como contribuciones a la denuncia internacional del terrorismo estatal. En tercer lugar, para quienes han atravesado una experiencia social traumática, la necesidad de contar lo visto resulta a menudo imperiosa -vital-, y ello puede ir asociado a la necesidad de recurrir a la ficción, como mediación simbólica que permite al 
testimoniante distanciarse de su pasado doloroso, y de esa manera ponerlo en palabras. En cuarto lugar, la ficción representa un elemento valioso y hasta indispensable en los relatos del sobreviviente-testigo, pues procura reparar las lagunas del testimonio concentracionario, vinculadas al hecho de que una de sus condiciones de existencia como discurso la constituye la imposibilidad de testimoniar de quienes no han sobrevivido al terrorismo dictatorial. En efecto, las estrategias de focalización interna ligadas al discurso ficcional permiten hacer como si quienes han muerto hablaran, esto es, dar voz a quienes no pueden tomar la palabra por fuera de un dispositivo ficcional.

Ahora bien: más allá de estas observaciones generales, es necesario señalar que la articulación entre testimonio y ficción en la literatura concentracionaria argentina de los años 80 no produce idénticos efectos de sentido cuando se trata de testimonios ficcionalizados de escritoras sobrevivientes, como en los casos de La Escuelita y Pasos bajo el agua, o tratándose de un relato literario que surge a partir de un testimonio ajeno, como en el caso de Recuerdo de la muerte. En la primera variante del género, el relato construye su validez como discurso factual, apoyándose no solo en el supuesto carácter irrefutable del haber estado alli sino, sobre todo, en la fragmentariedad del testimonio que surge de esa misma situación en el lugar de los hechos, siempre acotada a la propia subjetividad. Como hemos visto en los textos de Partnoy y Kozameh, el reconocimiento de la fragmentariedad ineludible del testimonio constituye un presupuesto del relato. A partir de dicho presupuesto, la apelación a la ficción representará una opción narrativa que el sobreviviente toma para posibilitar su testimonio - debido a la distancia ya señalada entre el relato ficticio y la experiencia traumática que narra-, e incluso para potenciar su alcance representativo -debido a la multiplicidad de voces a las que da lugar la ficción, así como por la fuerza simbólica que puede adquirir la recreación ficcional-. En tanto, en la segunda modalidad del género, la credibilidad del discurso como relato factual deja de residir en la voz del testigo, que el texto reelabora e incluso invisibiliza, y lo que se desarrolla frente al lector es una reconstrucción de cierta historia postulada como verídica. En términos más precisos, el relato ya no dice: estos han sido los acontecimientos, los cuento porque y tal como los vi y viví, sino: estos han sido los acontecimientos, los cuento tal como sostengo que han ocurrido. Se pasa, de esa manera, del escritor sobreviviente-testigo al escritor "historiador", uno que afirma la factualidad de los acontecimientos que relata, desde cierta posición subjetiva que construye a partir de la escucha de los testigos (LaCapra 57). En Recuerdo de la muerte, es precisamente la posición subjetiva del escritor lo que ha sido objeto de 
discusiones, porque se reduce a la identificación con un único testimonio, y porque dicha reducción parece resultar indisociable del uso de la ficción en el texto, que permitiría mitigar las exigencias de rigor histórico que operan sobre un relato concebido como factual. En efecto, el escritor "historiador" no deja de ser escritor: no hace historia sino literatura, aprovechando sus libertades creativas. Dichas libertades, en el texto de Bonasso, representan al mismo tiempo la forma que toma la inexactitud histórica del libro y un motivo básico de que el escritor haya producido un atrapante relato sobre la supervivencia al poder concentracionario, que alcanzó una amplia difusión en la Argentina. Así, la compleja interrelación entre testimonio y ficción que propone el texto habilita distintos y hasta contradictorios efectos de sentido.

\section{BIBLIOGRAFÍA}

Agamben, Giorgio. Lo que queda de Auschwitz. El archivo y el testigo. Homo Sacer III. Trad. Antonio Gimeno Cuspinera. Valencia: Pre-Textos, 2002.

Avelar, Idelber. Alegorías de la derrota. La ficción postdictatorial y el trabajo del duelo. Santiago de Chile: Cuarto Propio, 2000.

Badaró, Máximo y Anna Forné, eds. Memorias de la represión en Argentina y Uruguay: narrativa,s, actores e instituciones. Estocolmo: Institute of Latin American Studies, 2011.

Barnet, Miguel. "La novela testimonio: socio-literatura”. Unión 1 (1969): 99-122.

Betterman, Brian. Armar el rompecabezas. La memoria y la tortura en La Muerte y la doncella de Ariel Dorfman y La Escuelita de Alicia Partnoy. Jupiter: Florida Atlantic College, 2009.

Beverley, John. "Anatomía del testimonio". Revista de crítica literaria latinoamericana 25 (1987): 7-16.

Boccanera, Jorge, ed. Redes de la memoria. Escritoras exdetenidas. Testimonio y ficción. Buenos Aires: Instituto movilizador de Fondos Cooperativos, 2000.

Bonasso, Miguel. Recuerdo de la muerte. Buenos Aires, Bruguera, 1984.

Recuerdo de la muerte. Edición definitiva. Buenos Aires, Planeta, 1994.

Lo que no dije en Recuerdo de la muerte. Buenos Aires: Sudamericana, 2014.

Calveiro, Pilar. "Testimonio y memoria en el relato histórico". Acta Poética 27 (2006): 65-86.

Politica y/o violencia. Una aproximación a la guerrilla de los años 70. Buenos Aires: Norma, 2005.

Castillo, Carolina. "Rodolfo Walsh-1957/ Tomás Eloy Martínez-1973: testimonios entre las sombras del pasado argentino". María Coria et al. Escenas interrumpidas de la literatura argentina. Mar del Plata, Ediciones Suárez, 2006. 67-79.

Crenzel, Emilio. "Cambios y continuidades en la denuncia de las desapariciones en Argentina (1960-1983)”. Fermentum 46 (2006): 372-394. 
Dalmaroni, Miguel. La palabra justa: Literatura, crítica y memoria en la Argentina, 19602002. Mar del Plata: Melusina; Santiago de Chile: RIL, 2002.

Dri, Jaime. Testimonio de Jaime Dri. Movimiento Peronista Montonero. París: Consejo Superior. Secretaría de Prensa, 1978.

Erll, Astrid. Memoria colectiva y culturas del recuerdo. Estudio introductorio. Trads. Johanna Córdoba y Tatjana Louis. Bogotá: Universidad de los Andes, 2012.

Forné, Anna. "El género testimonial revisitado. El premio testimonio de Casa de las Américas (1970-2007)". El taco en la brea 1(2014): 216-232.

Fornet, Ambrosio. La coartada perpetua. México: Siglo XXI, 2001.

Foster, David. "Narrativa testimonial argentina durante los años del Proceso". Eds. René Jara y Hernán Vidal. Testimonio y literatura. Minnesota: Institute for the study of ideologies and literature, 1986. 138-154.

Violence in Argentine literature. Cultural responses to tirany. Columbia: University of Missouri Press, 1995.

Galich, Manuel. "Para una definición del género testimonio". Casa de las Américas 200 (1995): 124-125.

García, Victoria. "Testimonio literario latinoamericano: una reconsideración histórica del género". Exlibris 1 (2012): 371-389.

La obra testimonial de Rodolfo Walsh en el contexto argentino y latinoamericano de los años 60-70 (tesis doctoral). Buenos Aires: FFyL-UBA, 2014.

"Testimonio y literatura. Algunas reflexiones y tres realizaciones en la narrativa argentina: Walsh, Urondo, Cortázar”. Kamchatka. Revista de análisis cultural 6 (2015): 11-38.

Gilman, Claudia. Entre la pluma y el fusil. Debates y dilemas del escritor revolucionario en América Latina. Buenos Aires: Siglo XXI, 2012.

Goicochea, Adriana. El relato testimonial en la literatura argentina de fin de siglo. La Plata: Universidad Nacional de La Plata, 2008.

Graselli, Fabiana. Rodolfo Walsh y Francisco Urondo, el oficio de escribir. Tensiones y respuestas de una literatura peligrosa: prácticas estético- políticas y escritura testimonial. Tesis doctoral. Buenos Aires: Facultad de Ciencias Sociales, 2011.

Guillard, Amandine. "La metáfora de lo real en la poesía carcelaria de Alicia Kozameh". Escritural 6 (2012): 54-65.

Kozameh, Alicia. Pasos bajo el agua. Buenos Aires: Contrapunto, 1987.

Jelin, Elizabeth. Los trabajos de la memoria. Lima: Instituto de Estudios Peruanos, 2012.

LaCapra, Dominick. Historia y memoria después de Auschwitz. Trad. Marcos Mayer. Buenos Aires: Prometeo, 2009.

Logie, Ilse. "Más allá del «paradigma de la memoria». La autoficción en la reciente producción posdictatorial argentina”. Pasavento. Revista de Estudios Hispánicos 1 (2015): 75-89.

Longoni, Ana. Traiciones. La figura del traidor en los relatos acerca de los sobrevivientes de la represión. Buenos Aires: Norma, 2007.

Melón Pirro, Julio César. El peronismo después del peronismo. Buenos Aires: Siglo XXI, 2009. 
Morejón Arnaiz, Idalia. "Testimonio de una casa". Encuentro de la Cultura Cubana 40 (2006): 93-104.

Nofal, Rossana. La escritura testimonial en América Latina. Tucumán: Facultad de Filosofía y Letras de la Universidad Nacional de Tucumán, 2002.

"La guardarropía revolucionaria en la escritura de Laura Alcoba". El taco en la brea 1 (2014): 277-288.

Ochando Aymerich, Carmen. La memoria en el espejo: aproximación a la escritura testimonial. Barcelona: Anthropos, 1998.

Palazón Sáez, Gema. Memoria y escrituras de Nicaragua. Cultura y discurso testimonial en la Revolución Sandinista. París: Publibook, 2009.

Partnoy, Alicia. The Little School. Tales of disappearance and survival in Argentina. Pittsburgh: Cleis Press, 1998.

La Escuelita. Relatos testimoniales. Bahía Blanca: La Bohemia, 2006.

Pérez, Mariana Eva. Diario de una princesa montonera. 110\% verdad. Buenos Aires: Capital Intelectual, 2012.

Peris Blanes, Jaume. Historia del testimonio chileno: de las estrategias de denuncia a las políticas de memoria. Valencia: Universidad de Valencia, 2008.

“'La palabra es de ustedes, me callo por pudor': antiintelectualismo y emergencia del testimonio en Cuba"'. Atenea 508 (2013): 57-72.

Pfeiffer, Erna. "La historia como memoria personal y elaboración literaria. La escritura de Alicia Kozameh: Pasos bajo el agua (1987/2002)". Destiempos 2008. http://www.destiempos. com/n13/ErnaPfeiffer_13.htm

Piglia, Ricardo. "Hoy es imposible en la Argentina hacer literatura desvinculada de la política" (Reportaje de Ricardo Piglia a Rodolfo Walsh / marzo de 1970). Walsh, Rodolfo. Un oscuro día de justicia. Buenos Aires: Siglo XXI. 9-28.

Pittaluga, Roberto. "Miradas sobre el pasado reciente argentino: Las escrituras en torno a la militancia setentista (1983-2005)". Comps. Marina Franco y Florencia Levin. Historia reciente: perspectivas y desafios para un campo en construcción. Buenos Aires: Paidós, 2007. 125-152.

Pozzoni, Mariana. "Recuerdo de la muerte de Miguel Bonasso: entre la denuncia y la autocrítica. Una mirada exílica”. Malas Artes. Revista de Teoría y Crítica de la Cultura 1 (2012): 23-35.

Quintero Herencia, Juan Carlos. Fulguración de un espacio. El imaginario cultural de la Casa de las Américas. Rosario: Beatriz Viterbo, 2002.

Rama, Ángel. "Rodolfo Walsh: el conflicto de culturas en Argentina". Escritura 2 (1976): 279-304.

Salomone, Alicia. "Afirmación subjetiva y deber de memoria en La Escuelita, de Alicia Partnoy". Clepsidra. Revista Interdisciplinaria de Estudios sobre Memoria 1 (2014): 176-191

Sarlo, Beatriz. Escritos sobre literatura argentina. Buenos Aires: Siglo XXI, 2007. 2007.

Tiempo pasado: cultura de la memoria y giro subjetivo. Buenos Aires: Siglo XXI, 
Schaeffer, Jean-Marie. ¿Qué es un género literario? Trad. Juan Bravo Castillo y Nicolás Campos Plaza Madrid: Akal, 2006. ¿Por qué la ficción? Trad. José Luis Sánchez-Silva. Madrid: Lengua de Trapo, 2002. "Fictional vs. factual narration". Eds. Peter Hühn et al. The living handbook of narratology. Hamburgo: Hamburg University Press, 2013. hup.sub.uni-hamburg.de/lhn/ index.php?title=Fictional vs. Factual Narration\&oldid $=2048$.

Sillato, María del Carmen. "El testimonio en el marco de la ficción narrativa: los relatos de Alicia Kozameh". Erna Pfeiffer. Alicia Kozameh: ética, estética y acrobacias de la palabra escrita. Pittsburgh, Instituto Internacional de Literatura Iberoamericana, Universidad de Pittsburgh. 45-58.

Simón, Paula. "Exilio y autotraducción en la narrativa testimonial concentracionaria argentina. El caso de The Little School. Tales of Disappearance \& Survival in Argentina, de Alicia Partnoy". Orbis Tertius 19.20 (2014): 29-39.

Strejilevich, Nora. El arte de no olvidar. Literatura testimonial en Chile, Argentina y Uruguay entre los 80 y los 90. Buenos Aires: Catálogos, 2006.

Trigo, Pedro. Narrativa de un continente en transformación. Caracas: Universidad de Venezuela, 1976.

Urondo, Francisco. Los pasos previos. Buenos Aires: Adriana Hidalgo, 2011.

Walsh, Rodolfo. "Carta abierta de Rodolfo Walsh a la Junta militar". Operación masacre. Buenos Aires: De la Flor, 1984. 205-213.

Wieviorka, Annette. The era of the witness. Trad. Jared Stark. Nueva York: Cornell University Press, 2006. 